\title{
Intraarterial Microdosing: A Novel Drug Development Approach, Proof-of-Concept PET Study in Rats
}

\author{
Tal Burt ${ }^{1}$, Douglas C. Rouse ${ }^{1}$, Kihak Lee ${ }^{2}$, Huali Wu ${ }^{1}$, Anita T. Layton ${ }^{1}$, Thomas C. Hawk ${ }^{1}$, Douglas H. Weitzel ${ }^{1}$, \\ Bennett B. Chin ${ }^{1}$, Michael Cohen-Wolkowiez ${ }^{1}$, Shein-Chung Chow ${ }^{1}$, and Robert J. Noveck ${ }^{1}$ \\ ${ }^{1}$ Duke University, Durham, North Carolina; and ${ }^{2}$ Siemens Medical Solutions USA, Knoxville, Tennessee
}

\begin{abstract}
Intraarterial microdosing (IAM) is a novel drug development approach combining intraarterial drug delivery and microdosing. We aimed to demonstrate that IAM leads to target exposure similar to that of systemic full-dose administration but with minimal systemic exposure. IAM could enable the safe, inexpensive, and early study of novel drugs at the first-in-human stage and the study of established drugs in vulnerable populations. Methods: Insulin was administered intraarterially (ipsilateral femoral artery) or systemically to 8 CD IGS rats just before blood sampling or $60-\mathrm{min}{ }^{18} \mathrm{~F}-\mathrm{FDG}$ uptake PET imaging of ipsilateral and contralateral leg muscles (lateral gastrocnemius) and systemic muscles (spinotrapezius). The ${ }^{18} \mathrm{~F}-\mathrm{FDG}$ uptake slope analysis was used to compare the interventions. Plasma levels of insulin and glucose were compared using area under the curve calculated by the linear trapezoidal method. A physiologically based computational pharmacokinetics/pharmacodynamics model was constructed to simulate the relationship between the administered dose and response over time. Results: ${ }^{18} \mathrm{~F}-\mathrm{FDG}$ slope analysis found no difference between IAM and systemic full-dose slopes (0.0066 and 0.0061, respectively; $95 \%$ confidence interval [Cl], -0.024 to $0.029 ; P=0.7895$ ), but IAM slope was statistically significantly greater than systemic microdose $(0.0018$; $95 \% \mathrm{Cl},-0.045$ to $-0.007 ; P=0.0147)$ and sham intervention $(-0.0015 ; 95 \% \mathrm{Cl}, 0.023-0.058 ; P=0.0052)$. The pharmacokinetics/ pharmacodynamics data were used to identify model parameters that describe membrane insulin binding and glucose-insulin dynamics. Conclusion: Target exposure after IAM was similar to systemic full dose administration but with minimal systemic effects. The computational pharmacokinetics/pharmacodynamics model can be generalized to predict whole-body response. Findings should be validated in larger, controlled studies in animals and humans using a range of targets and classes of drugs.
\end{abstract}

Key Words: microdosing; intra-arterial; PET imaging; drug development; exploratory investigational new drug (eIND)

J Nucl Med 2015; 56:1793-1799

DOI: 10.2967/jnumed.115.160986

D rug development is a risky, expensive, lengthy, and errorprone process (1-11). In addition, vulnerable populations (e.g., elderly, pediatric) are routinely excluded from clinical trials because of safety concerns. A considerable amount of effort and resources

\footnotetext{
Received May 18, 2015; revision accepted Aug. 26, 2015.

For correspondence or reprints contact: Tal Burt, Department of Psychiatry and Behavioral Sciences, Duke University, P.O. Box 3862, 40 Duke Medicine Circle, Durham, NC 27710.

E-mail: tal.burt@duke.edu

Published online Aug. 27, 2015.

COPYRIGHT (c) 2015 by the Society of Nuclear Medicine and Molecular Imaging, Inc.
}

are spent ensuring the safety of testing, especially at the firstin-human stage. This leads to considerable expenses and delays in testing of new drugs in humans. Microdosing and other exploratory clinical trials have been proposed to address these challenges $(10,12-16)$.

Microdosing uses subpharmacologic doses (the smaller of $100 \mu \mathrm{g}$ or $1 / 100$ th of the estimated pharmacologically active dose, or noadverse-effects level) to safely test drugs in humans before traditional phase 1 . Microdosing has been strongly endorsed by both the Food and Drug Administration $(12,16)$ and the National Institutes of Health (NIH) (17) as a response to the critical path challenges (5) by offering safe and efficient translation of basic scientific discoveries into therapeutic applications. Microdosing, however, has seen limited use by drug developers because of the following limitations: only pharmacokinetic data can be obtained with traditional microdosing and uncertainty about extrapolating microdose data to the full-dose range $(13,18)$. Our drug development methodology, intraarterial microdosing (IAM), addresses these limitations (Fig. 1).

IAM combines features of microdosing and intraarterial drug delivery and is a form of targeted drug testing. The IAM methodology posits that targeted administration of drugs can allow sufficient information to be obtained on drug response to make valuable drug development decisions while benefitting from the considerable savings in time and resources that accompany the implied systemic safety. By administering a microdose of a drug calculated on a total-body basis, into an artery supplying a small region, full-dose exposure is generated in that region before returning systemically as a microdose (Fig. 1). It thus provides human-specific data when they are rarest-before the traditional phase 1 -allowing informed developmental decisions to be made 8-12 mo before traditional approaches $(19,20)$. Benefits include the ability to triage analogs with similar preclinical profiles, safe testing in vulnerable populations (e.g., pediatric, women, frail elderly, hepatically/renally impaired, poly comorbidity, poly pharmacy) and extreme environments (e.g., space, high altitudes), and reduction of the use of animals in human research $(10,21)$.

The goal of the study was to provide proof of concept of IAM in rodents. The primary hypothesis was that IAM leads to local effects that are similar to those after systemic administration. The secondary hypothesis was that the systemic exposure after IAM is minimal and similar to that after systemic administration of a microdose.

\section{MATERIALS AND METHODS \\ Ethical Statement \\ Approval from Duke Institutional Animal Care and Use Committee was obtained for the protocol and all amendments. Ethical animal handling and guidelines were adhered to throughout the experiments.}




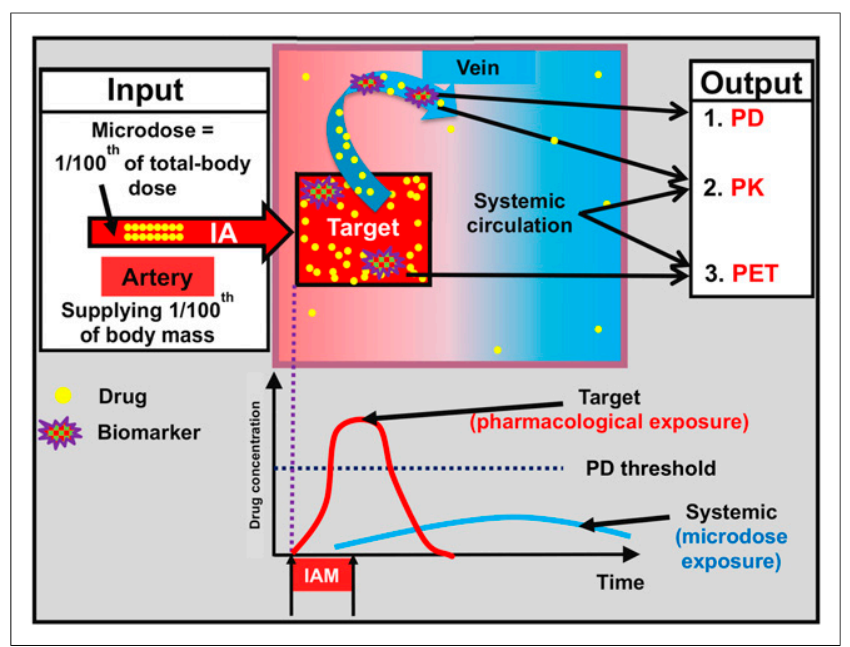

FIGURE 1. IAM. 1/100th of systemic pharmacologic dose administered to target that is $1 / 100$ th of body mass generates pharmacologic level exposure in that target while exposing rest of body to a microdose. $\mathrm{IA}=$ intraarterial; $\mathrm{PD}=$ pharmacodynamics; $\mathrm{PK}=$ pharmacokinetics.

Study Design. We compared intraarterial (femoral artery) administration with systemic (tail vein) administration of insulin as test article and glucose plasma levels and ${ }^{18} \mathrm{~F}-\mathrm{FDG}$ uptake as biomarkers. Measurements were made in 3 regions: ipsilateral (lower limb, side of IAM intervention), contralateral (lower limb, opposite side from the IAM intervention), and systemically. In the case of glucose levels, these 3 regions were represented by samples from ipsilateral and contralateral femoral veins and superior vena cava, respectively. In the case of ${ }^{18} \mathrm{~F}$-FDG uptake, these regions were represented by regions of interest (ROIs) in ipsilateral and contralateral lower limb leg muscles (lateral gastrocnemius) and paravertebral muscles (spinotrapezius), respectively.

\section{Experimental Groups (Table 1; Fig. 2)}

We compared the IAM with the following control groups: systemic full-dose group (SF) - effects of full, pharmacologic dose of insulin administered systemically (into tail vein); systemic microdose group (SM) — effects of systemic administration of microdose (tail vein) or the systemic (including contralateral) effects of a threshold pharmacologic insulin dose administered intraarterially, ipsilaterally (femoral artery); and sham/placebo intervention group (sham) —effects after no insulin administration (sham procedure or saline).

Numbers Analyzed and Baseline Data (Table 1). There were 17 experiments in 8 rats $(450.0 \pm 146.5 \mathrm{~g}$ [mean $\pm \mathrm{SD}$ ] $)$ distributed as follows (intervention): $n=3$ in IAM, $n=3$ in SF, $n=8$ in SM, and $n=3$ in sham. There were 14 imaging $\left({ }^{18} \mathrm{~F}-\mathrm{FDG}\right.$ uptake) experiments$n=2$ in IAM, $n=3$ in SF, $n=6$ in SM, and $n=3$ in sham-and 3 chemical (insulin and glucose plasma levels) experiments-IAM and SM (systemic and contralateral), all 3, contemporaneous, in the same animal.

\section{Randomization}

Animals were selected consecutively according to availability, on arrival from the vendor, Charles River Laboratories.

\section{Blinding}

The imaging analyses were done by analysts blinded to the expected effects.

Experimental Animals Housing and Husbandry. Animals were nonfasting CD IGS male rats, 10-14-wk-old (Charles River Laboratories).
All animals were kept on a normal 12-h day-night cycle, had free access to water, and were studied between 9 AM and 4 PM to minimize circadian variations of substrate metabolism. Animals were kept in 2-animal cages. Standard chow (Teklad Diet [Harlan Teklad Animal Diets \& Bedding]; $17.0 \%$ protein, $11.0 \%$ fat, and $<3.5 \%$ fiber) was used.

Animal Preparation. Rats were anesthetized by inhalation of $2 \%$ isoflurane (Isoflo; Abbott Laboratories) in 100\% oxygen in an induction box heated to $36^{\circ} \mathrm{C}$. The animals were placed on a heated PET/CT animal holder, which provided anesthesia through a nose cone (22).

Image Reconstruction and Analysis. Small-animal PET images were acquired on a hybrid microPET/CT Inveon MM scanner (Siemens Medical Solutions USA, Inc.) for $60 \mathrm{~min} .{ }^{18} \mathrm{~F}-\mathrm{FDG}(555.0$ $\mathrm{MBq} \pm 10 \%$ ) was obtained from PETNET.

Starting at the time of injection, the acquired list-mode data were binned into 12 image frames $(12 \times 300 \mathrm{~s})$. Reconstruction incorporated a filtered backprojection algorithm with a ramp filter and a cutoff frequency of 0.5 of the Nyquist frequency to obtain an image pixel size of $0.4 \times 0.4 \times 0.8 \mathrm{~mm}$ and an interplane spacing and slice thickness of $0.8 \mathrm{~mm}$ in a $128 \times 128$ matrix. The image reconstruction software provided for correction of radioactivity decay, random coincidences, dead-time losses, and photon attenuation (Inveon Acquisition Workplace 1.5SP1; Siemens Medical Solutions USA, Inc.). Photon attenuation was corrected for by CT-based attenuation maps as described previously (23).

ROIs were drawn on the coregistered CT image. Ellipsoid ROIs $\left(\sim 100 \mathrm{~mm}^{3}\right)$ were drawn for the lateral gastrocnemius muscles on the left (IAM, ipsilateral intervention) and right (contralateral control) hind legs. A cylindric ROI $\left(\sim 400 \mathrm{~mm}^{3}\right)$ was drawn on the spinotrapezius muscle (systemic control). The dynamic PET sequence was interpolated into the CT image space, and time-activity values (timeactivity curves) were recorded. All ROI processing was done using the Inveon Research Workspace (version 4.2; Siemens Medical Solutions, USA, Inc.).

Standardized uptake value (SUV) was calculated to normalize the radiotracer tissue concentrations to the injected dose and body weight according to the following equation (24):

$$
\mathrm{SUV}=\frac{\text { Mean tissue activity }(\mathrm{Bq} / \mathrm{mL})}{\text { Injected dose }(\mathrm{Bq}) / \text { body weight }(\mathrm{g})}
$$

The injected dose was measured from a dose calibrator (CRC-127R; Capintec Inc.). The tissue activity concentrations were obtained from the ROIs.

Procedures (Table 1). Insulin (Vetsulin; Merck Animal Health), diluted in saline, was administered in $0.5 \mathrm{~mL}$ over $1.5 \mathrm{~min}$ intraarterially to the left femoral artery in the IAM intervention group or systemically to the tail vein in the SF or SM intervention groups just before 60 -min ${ }^{18} \mathrm{~F}$-FDG uptake imaging of ipsilateral (gastrocnemius), contralateral (gastrocnemius), and systemic (spinotrapezius) muscles or sampling from respective veins (ipsilateral and contralateral femoral veins, and superior vena cava). In the sham intervention no insulin was administered, but the PET imaging was performed as in the IAM, SF, and SM interventions. Table 1 includes insulin dose and site of injection for each animal. Blood samples were not obtained during PET imaging procedures because of the confined position of the animals.

Slope Analysis (Fig. 2). ${ }^{18} \mathrm{~F}-\mathrm{FDG}$ uptake slopes were compared among IAM, SF, SM, and sham datasets (Table 1). The slopes of interventions were obtained from SUV-based time-activity curves of each dataset, with the $y$-axis representing the SUVs and the $x$-axis representing the time elapsed since ${ }^{18} \mathrm{~F}$-FDG administration. 
TABLE 1

Characteristics of 8 Charles River CD IGS Rats

\begin{tabular}{|c|c|c|c|c|c|}
\hline Animal & Experiment & Weight (g) & Intervention & Route & Outcome \\
\hline I & SM & 480 & Insulin, $0.0083 \mathrm{IU} / \mathrm{kg}$ & Tail vein & ${ }^{18} \mathrm{~F}-\mathrm{FDG}$ uptake \\
\hline \multirow[t]{3}{*}{ ॥ } & SM & 590 & Insulin, $0.0041 \mathrm{IU} / \mathrm{kg}$ & Tail vein & ${ }^{18} \mathrm{~F}-\mathrm{FDG}$ uptake \\
\hline & SF & 590 & Insulin, $3.39 \mathrm{IU} / \mathrm{kg}$ & Tail vein & ${ }^{18} \mathrm{~F}-\mathrm{FDG}$ uptake \\
\hline & SF & 573 & Insulin, $20.94 \mathrm{IU} / \mathrm{kg}$ & Tail vein & ${ }^{18} \mathrm{~F}-\mathrm{FDG}$ uptake \\
\hline III & Sham & 622 & No insulin & Not applicable & ${ }^{18} \mathrm{~F}-\mathrm{FDG}$ uptake \\
\hline IV & SF & 495 & Insulin, $48.48 \mathrm{IU} / \mathrm{kg}$ & Tail vein & ${ }^{18} \mathrm{~F}-\mathrm{FDG}$ uptake \\
\hline V & IAM SM (Sys + CL) & 267 & Insulin, $0.38 \mathrm{IU} / \mathrm{kg}$ & Left femoral artery & $\begin{array}{l}\text { Insulin and glucose } \\
\text { plasma levels }\end{array}$ \\
\hline $\mathrm{VI}$ & IAM SM (Sys + CL) & 294 & Insulin, 0.34 IU/kg & Left femoral artery & ${ }^{18} \mathrm{~F}-\mathrm{FDG}$ uptake \\
\hline VII & IAM SM (Sys + CL) & 289 & Insulin, $0.346 \mathrm{IU} / \mathrm{kg}$ & Left femoral artery & ${ }^{18} \mathrm{~F}-\mathrm{FDG}$ uptake \\
\hline VIII & Sham Sys + IL & 300 & Saline & Left femoral artery & ${ }^{18} \mathrm{~F}-\mathrm{FDG}$ uptake \\
\hline
\end{tabular}

Rats II, V, VI, VII, and VIII had multiple experiments either over different days (rat II) or contemporaneously (rats V, VI, VII, and VIII) for a total of 17 datasets composed of 14 experimental sets of imaging data ( ${ }^{18} \mathrm{~F}-\mathrm{FDG}$ ) and 3 sets of chemical data (insulin and glucose plasma levels). Contemporaneous data refer to IAM data that were obtained together with systemic/contralateral microdose control data, at same time in same animal.

SM (8 experiments) = systemic microdose (including systemic microdose [Sys] and contralateral microdose [CL] effects after IAM); SF (3 experiments) = systemic full-dose comparator; Sham (3 experiments) = systemic exposure after no insulin or saline interventions (animal VIII had 2 datasets: systemic [Sys] and ipsilateral [IL]); IAM (3 experiments) = intraarterial microdosing intervention and ipsilateral (target) effects.

The slopes were calculated using a linear fitting method and using the last 40-min time-activity curves (i.e., 20-60 min after injection). The first 20 -min time-activity curves were excluded because of the variability inherent in this non-steady-state period $(25,26)$. To test the primary hypothesis for efficacy and the secondary hypothesis for safety, the unpaired $t$ test was used with a 2-tailed $P$ value (0.05). To compare mean slope in IAM, SF, SM, and sham groups, renormalization was used to account for baseline differences.

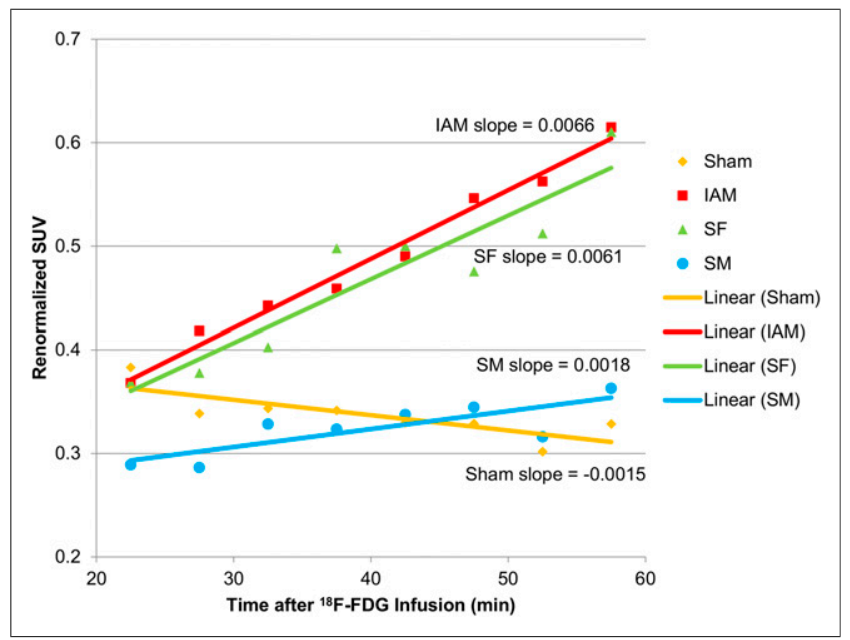

FIGURE 2. Slope analysis of ${ }^{18} \mathrm{~F}-\mathrm{FDG}$ uptake. Each slope represents data from each of 4 experimental groups: IAM $(n=2$; ROI: ipsilateral gastrocnemius) (A), SF ( $n=3$; ROI: ipsilateral gastrocnemius) (B), SM ( $n=$ 6; ROls: ipsilateral/contralateral gastrocnemius; spinotrapezius) (C), and sham ( $n=3$; ROls: ipsilateral gastrocnemius, spinotrapezius) (D). Slopes are mean of SUV-based time-activity curves.
Area-Under-the-Curve Analysis (Fig. 3; Supplemental Table 1 [supplemental materials are available at http://jnm.snmjournals.org]). Insulin and glucose levels were compared for 3 groups of venous samples before and after intraarterial insulin administration into the femoral artery at $45 \mathrm{~min}$ : ipsilateral (site of IAM) femoral vein (samples at 27, 56, 66, and $81 \mathrm{~min}$ ), contralateral femoral vein (samples at 29, 58, 67, and $84 \mathrm{~min}$ ), and systemic data (superior vena cava; samples at $8,37,63,69$, and $87 \mathrm{~min}$ ). The area under level versus time curve from 0 to the last measurable time point was calculated by the linear trapezoidal method. Because of varied last time points for the 3 groups, partial area under the curve over a common time interval was calculated for the purpose of comparison. Glucose levels were measured using Dry Chem 7000 (Heska Corp.). Insulin levels were measured using Insulin Elisa (ALPCO).

Modeling and Simulations (Supplemental Fig. 1). The model consists of 3 compartments, artery, vein, and interstitium, denoted by superscripts a, v, and i, respectively. Blood flow (denoted Q, black arrows; Supplemental Fig. 1) carries glucose and insulin. Cellular uptake of glucose and insulin (blue arrow) is represented in the interstitial compartment. The compositions of the arterial blood, venous blood, and interstitial fluid are assumed to be homogeneous. To predict insulin and glucose concentrations as functions of time, the model imposes conservation of mass in each of the compartments, for example, conservation of glucose in the interstitial compartment is given by:

$$
\begin{aligned}
\mathrm{V}^{\mathrm{i}} \frac{\partial}{\partial t} \mathrm{C}_{\text {glu }}^{\mathrm{i}}(\mathrm{t})= & -\mathrm{m}_{1} \mathrm{C}_{\text {glu }}^{\mathrm{i}^{\prime}}(\mathrm{t})-\mathrm{m}_{2} \mathrm{C}_{\text {ins }}^{\mathrm{i}^{\prime}}(\mathrm{t})+\mathrm{P}_{\text {glu }}^{\mathrm{a}}\left(\mathrm{C}_{\text {glu }}^{\mathrm{a}^{\prime}}(\mathrm{t})-\mathrm{C}_{\text {glu }}^{\mathrm{i}^{\prime}}(\mathrm{t})\right) \\
& +\mathrm{P}_{\text {glu }}^{\mathrm{v}}\left(\mathrm{C}_{\mathrm{glu}}^{\mathrm{v}^{\prime}}(\mathrm{t})-\mathrm{C}_{\mathrm{glu}}^{\mathrm{i}^{\prime}}(\mathrm{t})\right)
\end{aligned}
$$

where $\mathrm{C}$ denotes concentration; the subscripts glu and ins denote glucose and insulin, respectively; the prime notation denotes deviation from baseline concentration; and $\mathrm{V}^{\mathrm{i}}$ denotes the interstitial volume. 


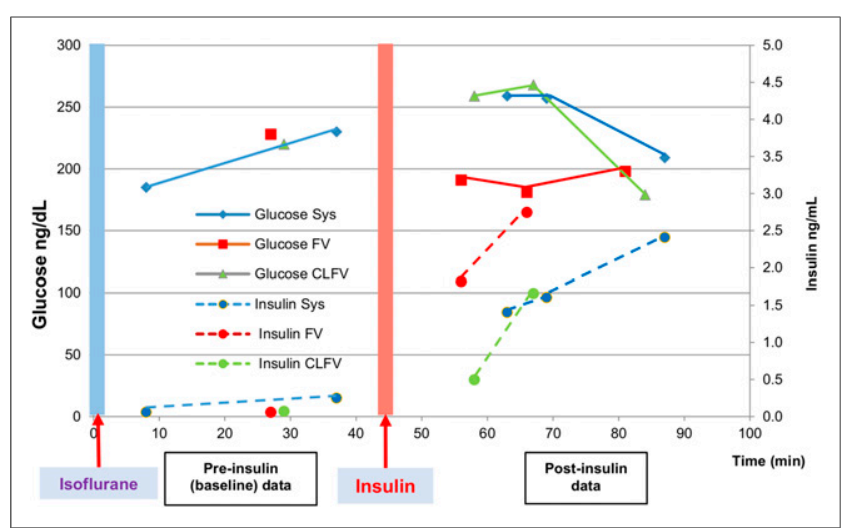

FIGURE 3. Plasma insulin and glucose levels after IAM into left femoral artery. Included are 3 datasets of insulin and glucose plasma levels (from animal V, Table 1). Each dataset is interrupted between preinsulin and postinsulin components because link cannot be assumed to be linear. CLFV = contralateral femoral vein samples (green; side opposite of IAM intervention); FV = ipsilateral femoral vein samples (red; side of IAM insulin administration); Sys = systemic (blue; superior vena cava) samples.

The term $\mathrm{m}_{1} \mathrm{C}^{\mathrm{i}^{\prime}}$ glu represents passive glucose diffusion into cells; $\mathrm{m}_{2} \mathrm{C}^{\mathrm{i}^{\prime}}$ ins represents facilitated uptake of glucose via glucose transporter 4, with glucose transporter 4 expression mediated by insulin; and the remaining terms represent vascular glucose fluxes (green arrows; Supplemental Fig. 1). Additional information about the model is provided in the supplemental information.

\section{RESULTS}

\section{${ }^{18}$ F-FDG Uptake Slope Analysis (Fig. 2)}

The injected dose for the 9 imaging sessions was $10.8 \pm 2.8$ $\mathrm{MBq}$ (mean $\pm \mathrm{SD}$ ). The baseline and slope of the ${ }^{18} \mathrm{~F}$-FDG uptake SUVs for IAM, SF, SM, and sham groups were measured from 14 time-activity curves from 9 sessions in 7 animals and are as follows: for IAM $(n=2)$, the baseline and slope were $0.2220 \pm$ 0.2319 and $0.0066 \pm 0.0017$, respectively. For SF $(n=3)$, the baseline and slope were $0.7547 \pm 0.1208$ and $0.0061 \pm 0.0019$, respectively. For SM $(n=6)$, the baseline and slope were $0.2542 \pm$ 0.1410 and $0.0018 \pm 0.0018$, respectively. For sham $(n=3)$, the baseline and slope were $0.3963 \pm 0.0826$ and $-0.0015 \pm 0.0009$, respectively. The IAM (0.0066) was similar and not statistically significantly different from the SF $(0.0061 ; 95 \%$ confidence interval [CI], -0.024 to $0.029, P=0.7895$ ). In addition, the IAM slope was statistically significantly greater than the SM mean slope $(0.0018$; $95 \% \mathrm{CI},-0.045$ to $-0.007, P=0.0147)$ and sham mean slope ( $-0.0015 ; 95 \% \mathrm{CI}, 0.023$ to $0.058, P=0.0052)$.

\section{Insulin and Glucose Plasma Levels (Fig. 3; Supplemental Table 1)}

Insulin levels (Fig. 3, dashed lines) were higher in the ipsilateral femoral vein than either the contralateral femoral vein or systemically (superior vena cava), and levels at the contralateral femoral vein were similar to those systemically.

Plasma glucose levels (Fig. 3, solid lines) reciprocated changes in insulin levels and were lower in the ipsilateral femoral vein than either the contralateral femoral vein or systemically (superior vena cava), and levels at the contralateral femoral vein were similar to those systemically.

\section{Simulation Results (Supplemental Information)}

Supplemental Figure 2 depicts the results of the simulation superimposed on the experimental data of insulin and glucose levels. Shown are changes in glucose and insulin concentrations in the arterial, venous, and interstitial compartments as functions of time.

\section{Adverse Events}

No adverse events were observed in association with the intraarterial intervention.

\section{DISCUSSION}

\section{Interpretation/Scientific Implications}

The results support our primary and secondary hypotheses. Ipsilateral (i.e., at the side of intraarterial insulin administration) insulin and glucose levels and ${ }^{18}$ F-FDG uptake were consistent with full-dose effects (primary hypothesis) whereas the effects on the rest of the body were consistent with subpharmacologic, or minimal effect (secondary hypothesis). Specifically, ipsilateral insulin levels increased, glucose levels decreased, and ${ }^{18} \mathrm{~F}-\mathrm{FDG}$ uptake into muscles increased when compared with contralateral and systemic controls. Our results show that target effects after intraarterial administration of test article are similar to those after systemic administration but with minimal systemic effects.

We chose insulin because of its rapid onset of action, the extensive familiarity with its effects, and the fact that biomarkers could be easily obtained after peripheral administration. Specifically, both imaging ( ${ }^{18} \mathrm{~F}-\mathrm{FDG}$ uptake) and chemical biomarkers (glucose and insulin plasma levels) were available to measure insulin effects. We chose the femoral artery because of ease of access and availability of a symmetric comparison, allowing controlled data to be obtained at the same time as the IAM intervention. Similarity with the human model of radial artery facilitates translation to human studies.

Though glucose and insulin plasma levels, before and after insulin administration, were obtained from 1 animal, they represent, in effect, 3 contemporaneous studies in the same biologic environment. The effects are in the target tissue (ipsilateral; gastrocnemius muscle), the contralateral target tissue, and systemic control (spinotrapezius muscles). The limited variability among these 3 groups can be appreciated by observing the preinsulin administration data: the 3 groups are almost overlapping. Soon after insulin is administered, a separation between the intraarterial and the systemic groups (systemic and contralateral) begins, whereas the systemic and contralateral groups remain overlapping. This contemporaneous experimentation property of IAM studies is unique in biomedical experimentation, in which control groups are almost always observed at different times and different subjects. This property has the potential to greatly reduce the variability inherent in control group experimentation, with the implied increase in power and reduction in costs and unnecessary exposure to risks.

\section{Generalizability/Translation}

Study results provide proof of concept of the IAM methodology by demonstrating that pharmacologic effects, both pharmacokinetics and pharmacodynamics, can be studied in limited target tissues by local administration and can faithfully represent effects after systemic exposure, and that with sufficiently small doses of test article (i.e., microdose) and area exposed, the rest of the body is exposed to safe, subpharmacologic concentrations. The IAM 
approach is consistent with the current internationally harmonized guidelines for exploratory clinical trials (ICH M3, Table 3) (12) requiring a toxicity study by intended route of administration (i.e., intraarterially in the IAM case).

IAM combines features of microdosing and intraarterial drug delivery. A microdose (1/100 of full dose) administered into an artery supplying $1 / 100$ of body mass will generate full-dose exposure in the target, allowing capture of pharmacodynamic data. The drug returning systemically is diluted $\times 100$, sparing the rest of the body full-dose exposure and meeting the regulatory definition of subpharmacologic microdose exposure with the implied developmental advantages $(12,16)$. The IAM artery will be chosen according to the expected effect in the target organ/tissue (Table 2). IAM allows study of the pharmacokinetics/pharmacodynamics continuum across the microdose/full-dose spectrum contemporaneously, in the same individual, thus enabling extrapolation of findings from the microdose to the full-dose range. With the IAM approach the entire continuum of exposure from microdose to full dose can be obtained in the target. This addresses the aforementioned limitations of traditional microdosing: lack of pharmacodynamics data and concerns about validity of extrapolation from microdose to full, pharmacologic dose.

Specifically, the IAM approach offers the following advantages over existing methods: limited duration of exposure of target tissues/organs to full concentrations of test articles; exposure of only a priori determined, clearly defined, small, and limited body mass to the test article; systemic exposure to no more than very low (microdose) concentrations; ability to detect acute changes in biomarkers indicative of drug efficacy or toxicity in humans including displacement of PET ligands at pharmacologically active concentrations (an advantage vs. traditional microdosing and preclinical testing); in the case of testing symmetric or bilateral organ/tissues (e.g., hands, kidneys, brain), the ability to use the same individual as their own control at the same time, a rarity in medical research; and ability to test and guide the choice and validity of endpoints and doses, in humans (both healthy volunteers and patients), before phase 1 .

The safety of the IAM approach will be maintained through the limited exposure to 1/100th of the total body, the limited duration (in range of seconds to minutes), and the ability to titrate the intraarterial dose from its subpharmacologic levels while observing for emerging toxicity signals (e.g., production of inflammation markers). That said, IAM will not be risk-free; however, it will provide a sufficiently safe, intermediate, proof-of-mechanism testing option that lies between the nonhuman studies and the full-dose, full exposure human experimentation.

\section{Applications (Table 2)}

IAM enables the capture of data relevant to the 3 pillars of survival of clinical pharmacology: tissue exposure, receptor binding, and pharmacology - the data used for go-no-go decisions in new drug development (27). The first 2 pillars, tissue exposure and receptor binding, can be obtained for all classes of drugs with IAM by labeling the drug with PET radioisotopes and using SUV measurements as surrogates of tissue concentrations (14). Displacement methodologies can inform receptor binding affinities. The third pillar, pharmacology, can be obtained for many drug classes that have pharmacologic action detectable within the timeframe of IAM (Table 2). For all other drug classes there are, arguably, intermediate biomarkers (e.g., metabolomic products)

TABLE 2

IAM Applications

\begin{tabular}{|c|c|c|}
\hline Drug & Organ/tissue & Biomarker \\
\hline $\begin{array}{l}\text { Nitrates, inotropes, adrenergic, muscarinic, } \\
\text { PDE5 inhibitors, neutral endopeptidase } \\
\text { inhibitors, natriuretic peptides }\end{array}$ & Peripheral vascular & $\begin{array}{l}\text { Vasodilation, vasoconstriction, } \\
\text { cGMP spillover measurement }\end{array}$ \\
\hline Anesthetics, analgesics (e.g., $\mathrm{Na}_{v} 1.7$ inhibitors) & $\begin{array}{l}\text { Peripheral } \\
\text { organ/tissue }\end{array}$ & Anesthesia, analgesia \\
\hline Triptans & Blood vessels & Analgesia, substance $P$ and CGRP levels \\
\hline Neuromuscular blocking agents & Skeletal muscles & Muscle relaxation/paralysis \\
\hline Chemotherapy & $\begin{array}{l}\text { Liver, kidney, brain, } \\
\text { breast }\end{array}$ & $\begin{array}{l}\text { Receptor binding (with PET imaging } \\
\text { of radiolabeled drug) }\end{array}$ \\
\hline Anticoagulants, antiplatelet & Blood & Coagulation parameters, platelet aggregation \\
\hline Immune modulators, antihistamines & Blood & Cytokines, allergic symptoms \\
\hline $\begin{array}{l}\text { Hypoglycemics, sodium glucose } \\
\text { cotransporter- } 2 \text { inhibitors, diuretics }\end{array}$ & Kidney & $\begin{array}{l}\text { Glucose levels, reabsorption in } \\
\text { proximal tubule (by }{ }^{18} \mathrm{~F}-\mathrm{FDG} \text { ) }\end{array}$ \\
\hline Antiarrhythmics & Heart & Electrocardiogram \\
\hline $\begin{array}{l}\text { Central nervous system stimulants and } \\
\text { depressants (e.g., hypnotics, sedatives, } \\
\text { anxiolytics), NMDA antagonists }\end{array}$ & $\begin{array}{l}\text { Central nervous } \\
\text { system }\end{array}$ & Neuronal activity (e.g., Wada Test) \\
\hline
\end{tabular}

Use of IAM to study pharmacologic effects (in addition to systemic pharmacokinetics, tissue pharmacokinetics, and receptor binding) will be feasible in drug classes that allow collection of biomarkers (or surrogate biomarkers) in time frame of seconds to minutes.

PDE5 = phosphodiesterase type 5; cGMP = cyclic guanosine monophosphate; CGRP = calcitonin gene-related peptide; NMDA = $N$-methyl-D-aspartate. 
that can be detected in the time frame of IAM (28). Drugs that take more than an hour to generate any measurable effects may not be compatible with IAM. IAM will not be appropriate for all developmental scenarios but will provide a valuable additional tool in which benefit-risk and economic considerations are favorable $(13,19,20,29-32)$.

The main limitations of this proof-of-concept study are the exploratory nature of the analyses and the small numbers of animals tested. Specifically, a more complete demonstration of equivalence of target effects after IAM with those after systemic administration would have required a noninferiority study design with larger sample size, which was beyond the scope of this proofof-concept study, the first to our knowledge to test this novel approach. Additional studies are required before the application of this approach in practice.

Experimental procedures were limited by the amount of blood that could be drawn from the animals (maximum of about $2.5 \mathrm{~mL}$ per animal) and difficulties simultaneously accessing the vessels for all 3 groups (IAM, contralateral, and systemic), thus limiting the number of time points available for analyses to 3-4 per group and introducing variability to collection time points, respectively. In addition, we were unable to obtain contemporaneous blood samples during the imaging procedures because of the confined position of the animals in the PET machine.

We are currently addressing these limitations in a human study. Specifically, during the human PET imaging procedures it is possible to obtain contemporaneous blood samples with the potential to greatly enhance the power of correlations between test article and biomarker plasma levels and imaging results. Up to 8 time points per group will be obtained.

\section{CONCLUSION}

In this proof-of-concept study, target exposure after IAM was similar to systemic full-dose administration but with minimal systemic effects. Our findings are being validated in larger studies in animals and humans using different targets and classes of drugs. IAM could enable safe, inexpensive, and early study of novel drugs at the first-in-human stage and the study of established drugs in vulnerable populations. The computational pharmacokinetics/ pharmacodynamics model can be generalized to predict whole-body response. IAM fits the call for disruptive, innovative, multidisciplinary, high-risk/high-return solutions to translational research challenges.

\section{DISCLOSURE}

The costs of publication of this article were defrayed in part by the payment of page charges. Therefore, and solely to indicate this fact, this article is hereby marked "advertisement" in accordance with 18 USC section 1734. Tal Burt holds a patent for IAM. Research reported in this publication was supported by the National Center for Advancing Translational Sciences of the National Institutes of Health (NIH) under award number UL1TR001117 and the NIH National Center for Research Resources (NCRR) grant number 1S10RR31792-1 through Duke Small Animal Translational PET/CT Center. Michael Cohen-Wolkowiez receives support for research from the NIH (1R01-HD076676-01A1), the National Center for Advancing Translational Sciences of the NIH (UL1TR001117), the National Institute of Allergy and Infectious
Disease (HHSN272201500006I and HHSN272201300017I), the National Institute for Child Health and Human Development of the NIH (HHSN275201000003I), the Food and Drug Administration (1U01FD004858-01), the Biomedical Advanced Research and Development Authority (BARDA) (HHSO100201300009C), the nonprofit organization Thrasher Research Fund (www.thrasherresearch. org), and industry for drug development in adults and children (www. dcri.duke.edu/research/coi.jsp). No other potential conflict of interest relevant to this article was reported.

\section{ACKNOWLEDGMENTS}

We thank Drs. Malcolm Rowland, Graham Lappin, and Mark Feinglos for their helpful comments on this study and manuscript. The content is solely the responsibility of the authors and does not necessarily represent the official views of the National Institutes of Health.

\section{REFERENCES}

1. Getz KA, Wenger J, Campo RA, Seguine ES, Kaitin KI. Assessing the impact of protocol design changes on clinical trial performance. Am J Ther. 2008;15: 450-457.

2. DiMasi JA, Feldman L, Seckler A, Wilson A. Trends in risks associated with new drug development: success rates for investigational drugs. Clin Pharmacol Ther. 2010;87:272-277.

3. Pammolli F, Magazzini L, Riccaboni M. The productivity crisis in pharmaceutical R\&D. Nat Rev Drug Discov. 2011;10:428-438.

4. Paul SM, Mytelka DS, Dunwiddie CT, et al. How to improve R\&D productivity: the pharmaceutical industry's grand challenge. Nat Rev Drug Discov. 2010;9: 203-214.

5. Innovation or stagnation: challenge and opportunity on the critical path to new medical products. Food and Drug Administration website. http://www.fda.gov/ ScienceResearch/SpecialTopics/CriticalPathInitiative/CriticalPathOpportunitiesReports/ ucm077262.htm. Accessed September 11, 2015.

6. Munos B. Lessons from 60 years of pharmaceutical innovation. Nat Rev Drug Discov. 2009;8:959-968.

7. Scannell JW, Blanckley A, Boldon H, Warrington B. Diagnosing the decline in pharmaceutical R\&D efficiency. Nat Rev Drug Discov. 2012;11: 191-200.

8. Coller BS, Califf RM. Traversing the Valley of Death: a guide to assessing prospects for translational success. Sci Transl Med. 2009;1:10cm9.

9. Henderson VC, Kimmelman J, Fergusson D, Grimshaw JM, Hackam DG. Threats to validity in the design and conduct of preclinical efficacy studies: a systematic review of guidelines for in vivo animal experiments. PLoS Med. 2013;10:e1001489.

10. Rowland M. Microdosing and the 3Rs. National Library of Australia website. http://trove.nla.gov.au/version/166532644. 2006. Accessed September 11, 2015.

11. van der Worp HB, Howells DW, Sena ES, et al. Can animal models of disease reliably inform human studies? PLoS Med. 2010;7:e1000245.

12. International Conference on Harmonization. Guidance on nonclinical safety studies for the conduct of human clinical trials and marketing authorization for pharmaceuticals M3(R2). In: International Conference on Harmonization of Technical Requirements for Registration of Pharmaceuticals for Human Use. Geneva, Switzerland: ICH Secretariat; 2009:8-16.

13. Lappin G, Noveck R, Burt T. Microdosing and drug development: past, present and future. Expert Opin Drug Metab Toxicol. 2013;9:817-834.

14. Bergström M, Grahnen A, Langstrom B. Positron emission tomography microdosing: a new concept with application in tracer and early clinical drug development. Eur J Clin Pharmacol. 2003;59:357-366.

15. Lappin G, Garner RC. Big physics, small doses: the use of AMS and PET in human microdosing of development drugs. Nat Rev Drug Discov. 2003;2: 233-240.

16. Guidance for industry, investigators, and reviewers exploratory IND studies. Food and Drug Administration website. www.fda.gov/downloads/drugs/ guidancecomplianceregulatoryinformation/guidances/ucm078933.pdf. Accessed September 11, 2015.

17. Collins FS. Reengineering translational science: the time is right. Sci Transl Med. 2011;3:90 cm 17 . 
18. Bertino JS Jr, Greenberg HE, Reed MD. American College of Clinical Pharmacology position statement on the use of microdosing in the drug development process. J Clin Pharmacol. 2007;47:418-422.

19. Wilding IR, Bell JA. Improved early clinical development through human microdosing studies. Drug Discov Today. 2005;10:890-894.

20. Yamane N, Igarashi A, Kusama M, Maeda K, Ikeda T, Sugiyama Y. Cost-effectiveness analysis of microdose clinical trials in drug development. Drug Metab Pharmacokinet. 2013;28:187-195.

21. Zimmer L. Can positron emission tomography facilitate paediatric drug development? Fundam Clin Pharmacol. 2008;22:595-598.

22. Suckow C, Kuntner C, Chow P, Silverman R, Chatziioannou A, Stout D. Multimodality rodent imaging chambers for use under barrier conditions with gas anesthesia. Mol Imaging Biol. 2009;11:100-106.

23. Chow PL, Rannou FR, Chatziioannou AF. Attenuation correction for small animal PET tomographs. Phys Med Biol. 2005;50:1837-1850.

24. Sugawara Y, Zasadny KR, Neuhoff AW, Wahl RL. Reevaluation of the standardized uptake value for FDG: variations with body weight and methods for correction. Radiology. 1999;213:521-525.

25. Byrnes KR, Wilson CM, Brabazon F, et al. FDG-PET imaging in mild traumatic brain injury: a critical review. Front Neuroenergetics. 2014;5:1-24.
26. Wu HM, Sui G, Lee CC, et al. In vivo quantitation of glucose metabolism in mice using small-animal PET and a microfluidic device. J Nucl Med. 2007;48: 837-845.

27. Morgan P, Van Der Graaf PH, Arrowsmith J, et al. Can the flow of medicines be improved? Fundamental pharmacokinetic and pharmacological principles toward improving phase II survival. Drug Discov Today. 2012;17: 419-424.

28. Kaddurah-Daouk R, Weinshilboum RM. Pharmacometabolomics: implications for clinical pharmacology and systems pharmacology. Clin Pharmacol Ther. 2014;95:154-167.

29. Croft M, Keely B, Morris I, Tann L, Lappin G. Predicting drug candidate victims of drug-drug interactions, using microdosing. Clin Pharmacokinet. 2012;51:237246.

30. Wagner CC, Langer O. Approaches using molecular imaging technology: use of PET in clinical microdose studies. Adv Drug Deliv Rev. 2011;63: 539-546.

31. Sugiyama Y, Yamashita S. Impact of microdosing clinical study: why necessary and how useful? Adv Drug Deliv Rev. 2011;63:494-502.

32. Maeda K, Sugiyama Y. Novel strategies for microdose studies using non-radiolabeled compounds. Adv Drug Deliv Rev. 2011;63:532-538. 